\title{
Ditos e não-ditos: o Brasil e as práticas de consumo nos autoanúncios das agências de publicidade nos anos 1950
}

Said and not said: Brazil and the consumption practices in the self-ads of advertising agencies in the 1950s

Dictado y no dictado: el Brasil y las prácticas de consumo en auto-anuncios de las agencias de publicidad en la década de 1950

João Anzanello Carrascoza

- Pós-doutor pela Universidade Federal do Rio de Janeiro (UFRJ)

- Doutor e mestre em Ciências da Comunicação pela Escola de Comunicação e Artes da Universidade de São Paulo (ECA-USP)

- Docente e pesquisador do Programa de Pós-Graduação em Comunicação e Práticas de Consumo, da Escola Superior de Propaganda e Marketing (ESPM-SP)

- Professor da ECA-USP

- Autor, entre outros Livros, de Estratégias criativas da publicidade, Do caos à criação publicitárias e Razão e sensibilidade no texto publicitário

- Coordenador do grupo de pesquisa "Comunicação, discursos e poéticas do consumo", da ESPM-SP

- Vice-coordenador do Grupo de Estudos de Novas Narrativas (GENN), da ECA-USP

- E-mail: jcarrascoza@espm.br

\section{Tânia Márcia Cezar Hoff}

- Pós-doutoranda na Pontifícia Universidade Católica de São Paulo (PUC-RS)

- Doutora em Letras pela Faculdade de Filosofia, Letras e Ciências Humanas da Universidade de São Paulo (FFLCH-USP) e mestre em Artes pela Escola de Comunicações e Artes (ECA-USP)

- Docente e vice-coordenadora do Programa de Pós-Graduação em Comunicação e Práticas de Consumo, da Escola Superior de Propaganda e Marketing (ESPM-SP)

- $\quad$ Autora, com Lourdes Gabrielli, do livro Redação publicitária

- Coordenadora do grupo de pesquisa "Comunicação, discursos e poéticas do consumo", da ESPM-SP

- E-mail: thoff@espm.br 


\section{Resumo}

Este artigo apresenta a síntese e os resultados da pesquisa "Ditos e não-ditos da narrativa publicitária: modernização e consumo no Brasil dos anos 1950", realizada pelos autores com o apoio do Centro de Altos Estudos da ESPM (CAEPM). São analisados os "ditos" da publicidade (aquilo que está expresso em seu discurso) e os seus não-ditos (os dizeres silenciados, à margem do que foi dito), a partir de um corpus que engloba autoanúncios das agências de propaganda veiculados na revista Publicidade e Negócios, ao longo da década de 1950 - período de intenso desenvolvimento econômico do país e de ampliação de suas práticas de consumo. A pesquisa se apoia em pressupostos teóricos da análise de discurso de linha francesa (Orlandi e Maingueneau) e da semântica argumentativa (Ducrot).

\section{PALAVRAS-CHAVE: PUBLICIDADE•ANÁLISE DE DISCURSO• MODERNIZAÇÃO•CONSUMO.}

\section{Abstract}

This article presents the synthesis and the results of the research known as "The said and the not said of the advertising narrative: modernization and consumption in the Brazil of the 1950s", conducted by the authors with the support of the Centro de Altos Estudos da ESPM (CAEPM) (Higher Studies Center of the Higher School of Advertising and Marketing). Our analysis of the "said" of advertising (that which is expressed in its discourse) and of its not said (the silenced sayings, laying aside what has been said), based on a collection that includes the self-advertisement of the advertising agencies published in the Publicidade e Negócios magazine throughout the 1950s decade - a period of intense economic development in Brazil and of broadening of its consumption practices. The research is based on theoretical assumptions of the French line of discourse analysis (Orlandi and Maingueneau) and argumentative semantics (Ducrot).

\section{KEYWORDS: ADVERTISING・DISCOURSE ANALYSIS • MODERNIZATION・CONSUMPTION}

\section{Resumen}

Este artículo presenta la síntesis y los resultados de la investigación "Dictados y no dictados de la narrativa publicitaria: modernización y consumo en el Brasil de los años 1950", realizada por los autores con el apoyo del Centro de Altos Estudios de la ESPM (CAEPM). Son analizados los "dictados" de la publicidad (aquello que está expresado en su discurso) y sus no dictados (los decires silenciados, al margen de lo que fue dicho), a partir de un corpus que incluye auto-anuncios de las agencias de publicidad vehiculados en la revista Publicidade e Negócios, a lo largo de la década de 1950 - período de intenso desarrollo económico de Brasil y de ampliación de sus prácticas de consumo. La investigación se sustenta en suposiciones teóricas de análisis del discurso de la línea francesa (Orlandi y Maingueneau) y de la semántica argumentativa (Ducrot). 


\section{ANO $12 \cdot$ NÚMERO $22 \cdot 1^{10}$ sem. $2015 \cdot$ ORGANICOM \\ DITOS E NÃO-DITOS: O BRASIL E AS PRÁTICAS DE CONSUMO NOS AUTOANÚNCIOS DAS AGÊNCIAS DE PUBLICIDADE NOS ANOS 1950}

narrativa publicitária traz em seu bojo valores, implícitos e explícitos, do contexto histórico no qual ela foi enunciada.
o texto de um anúncio, por exemplo, é estruturado por dizeres relativos fundamentalmente aos atributos do produto
ou serviço divulgado, mas que deixam à mostra representações sociais e certos investimentos no imaginário coletivo.

À margem desses dizeres, há um universo de não-dizeres que são silenciados: 1) pela impossibilidade natural de serem ditos se, em seu lugar, algo já o foi; e 2) pela estratégia discursiva adotada por seu enunciador, que privilegia determinados ditos, em detrimento de outros que não lhe convém mover por diversos motivos - o principal deles, certamente, porque não promovem tão bem a mercadoria anunciada quanto os dizeres escolhidos.

Esse é o nó ideológico que a publicidade nunca afrouxa, a chave de sua retórica, e, por isso mesmo, razão das mais veementes críticas endereçadas a ela. Se, como afirma George Péninou (2005), a narrativa publicitária está enraizada na criação de um mundo favorável ao produto, capaz de gerar empatia junto ao público-alvo, para que ela se sustente, sempre forçará o enunciador - 0 anunciante, embora a mensagem seja elaborada, por encomenda, por uma agência de propaganda - a eleger seus ditos em função dos objetivos de comunicação e em concílio com o plano de marketing estabelecido.

O interesse por investigar os ditos e os não-ditos da narrativa publicitária, esses dois vetores de análise do discurso que podem ser estudados em um sem-número de situações discursivas, e a nossa trajetória como pesquisadores das relações entre comunicação e consumo levaram-nos a fazer esta pesquisa sobre a publicidade nacional na década de 1950. Moveu-nos o desafio de averiguar esse período em virtude de nele se concretizar o crescimento acelerado do país, graças ao desenvolvimentismo do presidente Juscelino Kubitschek, que atraiu capital estrangeiro para viabilizar seu plano, sintetizado no slogan "50 anos em cinco".

Nosso objetivo foi, no plano geral, estudar o discurso produzido pelas agências de propaganda para divulgar seus próprios serviços no período de urbanização do Brasil e de modernização de seu parque industrial, e, no plano específico, discutir e analisar, por meio desses anúncios de época, o discurso publicitário e suas relações com o consumo (entendido não unicamente como ato de compra, mas, sobretudo, como prática sociocultural então em franco alargamento no país).

A mencionada delimitação temporal nos permitiu trabalhar com a memória discursiva, buscando na narrativa publicitária os imaginários que teceram os alicerces da cultura do consumo no Brasil. Essa década em que a cidade se instituiu como referência de imagem da nação e em que a industrialização, pelo menos no âmbito do desejo, passou a apontar outros modos de viver, foi particularmente rica no que se refere aos imaginários, pois o novo Brasil - ainda em construção - não existia senão em narrativas, que, longe de serem "fantasiosas" ou "falsas", produziram efeitos de verdade e alimentaram a formação de nossas subjetividades urbanas.

Nessa perspectiva, levamos em conta as duas formas de estruturação da memória coletiva postuladas por Michel Pollak (1992), que nos auxiliaram a compreender a narrativa publicitária como um documento de época: segundo esse autor, existe uma "memória oficial" que seleciona e ordena os fatos segundo certos critérios como zonas de sombra, silêncios, esquecimentos e repressões; mas também existem as "memórias subterrâneas", ligadas a quadros familiares, grupos étnicos, políticos etc. que transmitem e conservam lembranças proibidas, reprimidas ou ignoradas.

\section{A METODOLOGIA DE PESQUISA}

Definimos as edições da revista Publicidade e Negócios, publicadas ao longo da década de 1950, como fonte a partir da qual formamos dois corpora de peças publicitárias: o primeiro e principal corpus de análise composto por autoanúncios de 
agências de propaganda e, nele, estudamos os imaginários de modernização e de consumo e como foi construída a narrativa publicitária da época; já o segundo corpus, composto por peças publicitárias de anunciantes em geral, serviu-nos para aprofundar aspectos que pediam informações adicionais, além daquelas encontradas no corpus principal.

Dirigida principalmente a empresários e a profissionais de comunicação, essa revista veiculava publicidade de agências de propaganda, de veículos de comunicação e de fornecedores em geral. Os temas abordados privilegiavam o Brasil urbano, o mundo empresarial, as formas de comunicação e os novos modos de se administrar. No mercado editorial da época, composto por revistas voltadas ao consumidor final que tematizavam a vida cotidiana, dedicando-se às questões do universo feminino, da cultura brasileira e dos costumes da vida moderna, Publicidade e Negócios se constituía numa voz dissonante, por dirigir-se a um público segmentado - era a única publicação a tratar de propaganda na década estudada e por tematizar o mundo dos negócios, a racionalidade da produção e das vendas no contexto da modernização brasileira, bem como divulgar a importância de se fazer publicidade. Constituía-se, portanto, num arauto das novidades, do modo de vida e dos valores da época.

Com tiragem quinzenal, a revista apresentava edições regulares e especiais. Em cada edição regular, constatamos a veiculação de um número médio de três anúncios de agências, sem contar os de anunciantes e fornecedores (que também podem ser considerados, pois materializavam a ideia de progresso do país em suas narrativas), o que nos levou a quase mil anúncios, durante os anos 1950, dos quais selecionamos aproximadamente dez por cento (cem anúncios), que constituíram o nosso corpus principal de análise.

A principal orientação teórico-metodológica da pesquisa foi a análise de discurso de linha francesa, já que entendemos a narrativa publicitária como um conjunto de enunciados - de peças publicitárias - que nos permite identificar os modos de ver e de dizer (e de não dizer) em um dado contexto sócio-histórico. Assim, interessou-nos principalmente trabalhar com os ditos e os não-ditos, como antecipamos, inter-relacionando comunicação, consumo e situação socioeconômica e cultural da sociedade brasileira, e também com o imaginário, concebido como memória discursiva e abordado a partir da noção de interdiscurso (Orlandi, 2000).

Estruturamos a pesquisa em duas grandes partes: 1) a análise dos ditos da modernização e do consumo do Brasil dos autoanúncios das agências veiculados durante os anos 1950 na revista $P \& N$; e 2) a análise dos não-ditos a esse respeito que os mesmos discursos deixaram de enquadrar (ou seja, as narrativas que eles silenciaram).

\section{OS DITOS E NÃO-DITOS IDENTIFICADOS E ANALISADOS}

\section{Os ditos dominantes}

Um dos ditos mais frequentes do nosso corpusprincipal afirmava que o consumo havia se disseminado a um tal ponto no país $\neg$-graças ao aumento da nossa produção industrial e ao acesso aos bens importados -, que, em qualquer região do território nacional, o cidadão brasileiro poderia encontrar e adquirir produtos representativos da vida moderna. As novas práticas de consumo, que então surgiam, estariam ao alcance não só dos habitantes da cidade de São Paulo, que se transformara no grande polo de industrialização, mas de outras capitais do Brasil e, também, de cidades menores. 
Outro dito, muito enfatizado, divulgava o crescimento econômico do país com dados estatísticos informados pelo governo e realçava que essa expansão ocorria em todo tipo de negócios para a indústria e o comércio (alimento, vestuário, saúde, educação etc.). As formações discursivas mais usuais traziam expressões voltadas ao conforto, ao bem-estar e à vida moderna.

Nesse contexto, as agências de propaganda adotavam, independentemente de seu porte, um posicionamento comum, corporativo, afirmando que a maneira mais segura para uma empresa ampliar suas vendas era por meio de seu investimento em publicidade. Só a expertise publicitária era capaz de lhe abrir todos os mercados que, então, se alargavam. A publicidade era propriamente "dita" como aquela que estreitava a distância entre o produto novo (roupas, eletrodomésticos, brinquedos etc.) e o consumidor curioso por experimentá-lo.

Desse dito advinha outro, intensamente explorado pelas agências, por meio do qual elas "chamavam" os anunciantes para investirem com urgência em publicidade. Não bastava anunciar, era preciso fazê-lo de imediato não apenas para ampliar a participação no mercado, mas também para não perder market share, já que a competição se acirrava e todas as empresas, dos mais variados segmentos, deveriam aproveitar ao máximo aquele período de prosperidade.

Outros ditos, igualmente relevantes, na centena de autoanúncios que analisamos foram: 1) a diversidade de produtos industriais que traziam novas práticas de consumo para a sociedade brasileira (incluindo aqui o consumo dos primeiros programas televisivos); 2) o apoio das agências de propaganda ao ímpeto desenvolvimentista do governo; e 3) a posição das agências, menos servil em relação aos anunciantes como era no início dos anos 1950, quando o país estava sob o comando de Getúlio Vargas e, então, já na gestão de Juscelino Kubitschek, associada a um tipo de "aconselhamento" fundamental ao negócio de seus clientes.

\section{Os não-ditos correspondentes}

A semântica argumentativa, nos estudos de Oswald Ducrot (1987), esclarece-nos que o não-dito complementa o que foi dito. 0 pressuposto e o subentendido são formas do não-dizer, daquilo que está implícito no dizer. 0 pressuposto se dá no âmbito da própria linguagem (no ato ilocutório), enquanto o subentendido se manifesta no contexto.

Tomando os ditos presentes em maior número no corpus analisado, que resumimos acima, fomos confrontá-los com 0 contexto da época, para encontrarmos os não-ditos relevantes, tanto pressupostos como (principalmente) subentendidos.

Vimos que o apelo dominante nos anúncios das agências (para não dizer quase o único), durante a década de 1950, era a urgência de vender: os anunciantes não podiam perder a oportunidade de ampliar suas vendas, fosse qual fosse seu produto ou serviço. Essa "obsessão" argumentativa pressupunha haver um contingente de consumidores capazes de comprar tudo o que se oferecia à época.

Se, de fato, o país passava pela segunda fase de sua industrialização - a substituição das importações - e, conforme Celso Furtado (1978, p. 141), "os investimentos se orientavam para a satisfação de uma demanda reprimida", ou seja, em direção ao "desenvolvimento para dentro", o consumo, no entanto, se restringia invariavelmente ao universo urbano. As massas rurais continuavam isoladas dos benefícios do desenvolvimento e se constituíam em um dos limites estruturais de sua possibilidade política (Cardoso; Faletto, 1973, p. 106).

A esse respeito, ainda há outro não-dito fundamental: o padrão de urbanização brasileira, oriundo da industrialização baseada na produção fordista, foi tipicamente metropolitano, "criando enormes periferias sem as mínimas condições de 
habitabilidade, criadas com o argumento de absorver os grandes contingentes de trabalhadores que se instalavam nas cidades, especialmente as da Região Sudeste" (Carvalho, 2002, p. 49).

No insistente dizer "é hora de vender", que se disseminava nos autoanúncios analisados da primeira metade dos anos 1950 , os publicitários mantinham, igualmente, em total silêncio, a inflação alta que assolava o Brasil. Esse mesmo não-dito estava colado no apelo, tantas vezes enunciado, das agências, que diziam utilizar os mais variados tipos de recursos retóricos para vender a todos os tipos de consumidores.

Outro dito importante que apontamos era a argumentação numérica, sobretudo na segunda metade da década em questão. Coextensivo a esse dito, havia um não-dito, subentendido, que ganhava relevância ante a conjuntura política da época: a aliança populista-desenvolvimentista que existia, sob o comando de Juscelino Kubitschek. Obviamente, era estratégico para as agências nacionais e estrangeiras (que buscavam atender às empresas estatais e as indústrias estrangeiras com fábricas inauguradas no país) plasmarem, em seu discurso, os números do crescimento divulgados pelo governo, buscando, assim, empatia com as forças dessa aliança.

Paulo Roberto de Almeida (2007) afirma que as altas taxas de crescimento econômico do governo de Juscelino tiveram como preço o desequilíbrio das contas públicas e da elevação generalizada dos preços. A construção de Brasília, nova capital do país, foi um dos fatores determinantes do aumento significativo da dívida nacional. A ênfase do desenvolvimentismo na industrialização enfraqueceu a produção agrícola e a oferta de consumo não chegava ao campo. 0 êxodo rural levou pobreza e violência às grandes capitais do Sudeste. 0 desenvolvimento econômico do país no fim dos anos 1950 era grandioso, mas os problemas conjunturais da época, silenciados na publicidade, também.

\section{CONSIDERAÇÕES FINAIS}

As agências de propaganda, ao colocar em circulação em seus anúncios certas formações discursivas - seus ditos mais frequentes, que sustentam a "memória oficial" -, deixaram de se valer de outras, que constituem os seus não-ditos, sedimentados na "memória subterrânea" social.

No conjunto de anúncios analisados, encontramos pela isotopia do não-dito toda uma "narrativa" que omitiu os conflitos econômicos e sociais do Brasil dos anos 1950. Capítulos marcantes dessa história "inaudita" são as empresas (incluindo as agências de propaganda) que sucumbiram, o aumento da pressão inflacionária, a concentração de renda que se tornou inerente ao processo de industrialização do país (Furtado, 1978, p. 147), o êxodo rural e o agravamento das tensões sociais, entre outros.

Os ditos e não-ditos identificados e analisados revelam os regimes de visibilidade da modernização e do consumo no Brasil da década de 1950, pois é por meio da narrativa publicitária que, no âmbito comunicacional, as transformações de nossa realidade são difundidas e ganham sentido de tal modo que engendraram as contemporâneas culturas do consumo. A narrativa publicitária veiculada na revista Publicidade e Negócios, por exemplo, enreda e torna visíveis novas práticas de consumo, convidando e convocando os empresários a aderirem aos novos tempos e à publicidade. Num plano ampliado, a narrativa publicitária constrói os novos modos de ver e de ser visto no período estudado: trata-se, conforme Fernanda Bruno e outros (2010, p. 8), de uma nova ordenação do olhar e, portanto, dos regimes de visibilidade, os quais consistem "não tanto no que é visto, mas no que torna possível o que se vê". 
O país do presente e do futuro, ou seja, o Brasil da modernização consubstancia-se na experiência urbana, que faz emergir uma cenografia moderna, marcada pelos ambientes construídos e pelos espaços repletos de transeuntes; na visualidade promovida pelas fábricas, grandes edificações que delimitam a paisagem natural, imprimindo novos ritmos e novos rituais de vida cotidiana; bem como na racionalização da produção que enfatiza a importância da industrialização e da mercadoria.

A partir do corpus analisado, podemos dizer que a publicidade constitui um dos principais regimes de visibilidade da época que confere sentido à metanarrativa da modernização e do consumo no Brasil. Nessa perspectiva, a revista Publicidade $e$ Negócios, embora se destine a um segmento de público específico e tenha uma missão editorial bem demarcada, compõe, juntamente com as demais revistas do mercado editorial brasileiro dos anos 1950, o conjunto das enunciações que narram e tornam visíveis as transformações socioculturais do Brasil. 0 consumo promove os regimes de visibilidade, ou seja, as narratividades e também as materialidades necessárias para a produção da nova realidade brasileira ou o Brasil do futuro.

Nas duas últimas décadas, o Brasil tem apresentado equilíbrio econômico e crescimento sólido, com melhor distribuição de renda e inclusão das classes menos favorecidas ao consumo de bens antes inatingíveis. 0 país vem ganhando, igualmente, maior expressão geopolítica, e as empresas multinacionais aqui sediadas encontram-se às voltas com novos modelos de negócios.

Instigante, nesses tempos de certa semelhança com os "anos dourados" do governo JK, será investigar também os autoanúncios das agências de propaganda na contemporaneidade. De que maneira elas têm tangibilizado nos seus ditos essa "modernizacão social" e as novas práticas de consumo e quais os seus mais significativos não-ditos? São desafios abertos para nós, pesquisadores - e para os próprios anunciantes, que, queiram ou não, "revelam", pela publicidade, os seus investimentos em certas estratégias discursivas.

\section{REFERÊNCIAS}

ALMEIDA, Paulo Roberto de. As relações econômicas internacionais do Brasil dos anos 1950 aos 80 . Revista Brasileira de Política Internacional, Rio de Janeiro, v. 50, n. 2, dez. 2007.

BRUNO, Fernanda et al. (Org.). Vigilância e visibilidade: espaço tecnologia e identificação. Porto Alegre: Sulina, 2010.

CARDOSO, Fernando Henrique; FALETTO, Enzo. Dependência e desenvolvimento na América Latina: ensaio de interpretação sociológica. 2. ed. Rio de Janeiro: Zahar Editores, 1973.

CARVALHO, Edemir de. Cidades brasileiras, crescimento e desigualdade social. Org \& Demo, Unesp-Marília, n. 3, p. 45-54, 2002.

DUCROT, Oswald. O dizer e o dito. São Paulo: Pontes, 1987.

FURTADO, Celso. A hegemonia dos Estados Unidos e o subdesenvolvimento da América Latina. 3. ed. Rio de Janeiro: Civilização Brasileira, 1978.

ORLANDI, Eni Puccinelli. Análise de discurso: princípios e procedimentos. 2. ed. Campinas: Pontes, 2000. 


\section{ANO $12 \cdot$ NÚMERO $22 \cdot 1^{10} \mathrm{sem} .2015 \cdot$ ORGANICOM \\ DITOS E NÃO-DITOS: O BRASIL E AS PRÁTICAS DE CONSUMO NOS AUTOANÚNCIOS DAS AGÊNCIAS DE PUBLICIDADE NOS ANOS 1950}

PÉNINOU, George. La comunicación publicitária. In: TOIRAC, Yanet; MUNÕZ, Rosa (Org.). Selección de lecturas sobre fundamentos de publicidad. Havana: Editorial Félix Varela, 2005.

POLLACK, Michel. Memória, esquecimento, silêncio. Estudos Históricos, Rio de Janeiro, v. 2, n. 3, Cpdoc, p. 3-15, 1989.

Artigo recebido em 29.12.2014 e aprovado em 01.06.2015. 